\title{
Involuntary Psychiatric Hospitalization and Risk Management: The Ethical Considerations
}

\author{
Richard C. Christensen, MD, MA \\ University of Florida, Gainesville Florida
}

Follow this and additional works at: https://jdc.jefferson.edu/jeffjpsychiatry

Part of the Psychiatry Commons

Let us know how access to this document benefits you

\author{
Recommended Citation \\ Christensen, MD, MA, Richard C. (1993) "Involuntary Psychiatric Hospitalization and Risk Management: \\ The Ethical Considerations," Jefferson Journal of Psychiatry. Vol. 11 : Iss. 2 , Article 9. \\ DOI: https://doi.org/10.29046/JJP.011.2.006 \\ Available at: https://jdc.jefferson.edu/jeffjpsychiatry/vol11/iss2/9 \\ This Article is brought to you for free and open access by the Jefferson Digital Commons. The Jefferson Digital \\ Commons is a service of Thomas Jefferson University's Center for Teaching and Learning (CTL). The Commons is \\ a showcase for Jefferson books and journals, peer-reviewed scholarly publications, unique historical collections \\ from the University archives, and teaching tools. The Jefferson Digital Commons allows researchers and interested \\ readers anywhere in the world to learn about and keep up to date with Jefferson scholarship. This article has been \\ accepted for inclusion in Jefferson Journal of Psychiatry by an authorized administrator of the Jefferson Digital \\ Commons. For more information, please contact: JeffersonDigitalCommons@jefferson.edu.
}




\title{
Involuntary Psychiatric Hospitalization and Risk Management: The Ethical Considerations
}

\author{
Richard C. Christensen, M.D., M.A.
}

\begin{abstract}
During an era where physicians go to great lengths to limit personal risk and ensure self-protection from lawsuits, psychiatrists may be inclined to err on the side of involuntarily hospitalizing patients who have been briefly evaluated in the emergency room or clinic setting. However, conscientious treatment decisions, particularly those pertaining to involuntary psychiatric hospitalization, need to address at least two fundamental ethical concerns: the patient's best interests and the clinician's motives. This article discusses the moral components involved in clinical decision making and presents a case example which highlights the ethical implications of involuntary psychiatric hospitalizations.
\end{abstract}

Several years ago, a colleague in the field of medical ethics reminded me that every treatment decision possesses three facets which must be examined by the decisionmaker: the clinical, the legal and the ethical. In other words, one must be prepared to evaluate every treatment choice for its medical appropriateness, its legal defensibility and its ethical soundness. I believe physicians, in general, are cognizant of the clinical concerns driving treatment choices and are becoming increasingly more aware of their legal responsibilities based upon principles of prudent risk management. However, I have frequently wondered how attuned psychiatrists are to identifying and addressing the ethical tension created by moral principles and values which threaten at times to come into sharp conflict in the clinical setting. Nowhere has this become more evident than in the hospital emergency room where I have often been compelled to hospitalize persons against their wishes, to "break" confidentiality for the purpose of protecting the patient, and even deny people access to the most appropriate health care services because of their inability to pay. To reduce these treatment decisions to only their clinical and legal foundations is to perilously ignore their moral dimensions. I understand this to be no trivial oversight since it is the moral aspect of a decision which reminds physicians that the patient before them is first and foremost a person, someone who is owed, as Paul Ramsey writes, a "moral quality of action and attitude" by the physician who steps into a relationship with them (1).

Richard C. Christensen, M.D., M.A. is Chief Resident in the Department of Psychiatry at The University of Florida in Gainesville. 
At two a.m., in the rush of a busy emergency room, it may be too much to expect a harried on-call psychiatrist to assume the role of a moral philosopher. But one does not need to be a philosopher-physician to identify, consider and reason about the ethical concerns involved in one of the most frequently encountered psychiatric emergency situations confronted by the consult-liaison psychiatrist: the decision to hospitalize a patient against his/her wishes.

Theoretically, commitment laws are based on the presumption that the patient is not only mentally ill, but also suffers from a severe impairment related to the underlying mental illness which renders them dangerous to themselves or others, or neglectful of their basic human needs. Most states provide for a period of commitment which is relatively brief (e.g., 48 to 72 hours), and designed primarily for crisis intervention and observation. It is this type of involuntary hospitalization which is commonly initiated by the emergency room psychiatrist. The frequency of this clinical occurrence is well-documented in a 1986 Client/Patient Sample Survey sponsored by NIMH which found that noncriminal involuntary admissions to both public and private psychiatric hospitals accounted for 27 percent of all inpatient admissions (2).

From an ethical perspective, the dilemma is usually framed as a tension between society's obligation to protect its members by providing care and safety to those debilitated by the ravages of mental illness versus the individual's right to be a self-determining, autonomous agent who is responsible for his/her own life choices. Figured into this matrix, is the physician's obligation to promote the good of the patient and not to inflict harm, duties based squarely on the ethical principles of beneficence and nonmaleficence, respectively (3).

Concretely, however, there is great disagreement at times over how suicidal, dangerous or helpless a person must be to justify overriding their wishes and hospitalizing them (4). To involuntarily commit a person is to deny them the most fundamental of all human rights, their right to liberty and self-determination. Whether the abridgement of these rights is justified on the basis of an appeal to paternalism (i.e., protection of the patient), or grounded in an obligation to protect innocent third parties, it is a step which ought never be taken hastily and without consideration of the moral components of the decision.

Although this may appear to be a rather obvious observation, at times there appears to be a certain nonreflective ease with which clinicians involuntarily commit patients for short-term psychiatric hospitalizations after brief evaluations in the emergency room. During post-call conferences, as well as informal discussions with other psychiatrists, our justifications frequently appear to be reduced to primarily clinical and/or legal concerns. This implies that either ethical concerns are playing no role in our decision making processes or they are remaining unaddressed, buried beneath the more prominent clinical indications and, at times, legal risks impelling the decision to admit a person against his/her wishes.

It can be argued that morally conscientious treatment decisions, particularly those pertaining to involuntary psychiatric hospitalization, need to address at least two critically relevant ethical concerns: assessment of the patient's best interest and 
evaluation of the clinician's motives. Although there are numerous other moral considerations associated with this specific clinical situation, the intention in this brief paper is not to posit an exhaustive list of ethical concerns which must be examined by the psychiatrist whenever the situation of involuntary commitment arises. Rather, the attempt here is to provide a starting point where practical ethical reasoning can become integrated into the clinical decision making process. Attending to questions related to the patient's best interest, and physician motives, serves to address fundamental moral concerns about not only the act, but the agent as well.

\section{CONSIDERING THE PATIENT'S BEST INTEREST}

Assessing the patient's best interest strikes at the very core of the involuntary hospitalization dilemma since the psychiatrist is faced with the prospect of interfering with someone's personal liberty based on the duty to protect or promote the good of those who cannot adequately take care of themselves. Although most physicians unarguably would acknowledge a moral duty to act in the patient's best interests, the assessment of what that entails in particular clinical situations is frequently ambiguous and uncertain.

What constitutes a patient's best interests traditionally has been viewed rather narrowly within the Hippocratic tradition as the physician calculating medical benefits and harms for the patient. Robert Veatch has suggested, however, that if physicians are to honestly attempt to assess what is "in the interest" of the patient, they need to consider what the patient's concept of their personal welfare entails, even if the patient's notion is broader and more expansive than immediate medical concerns alone (5). Clearly, facilitating access to the mental health care system may be of supreme benefit to one patient, while for another, the loss of an already limited personal autonomy or the burden associated with the stigma of being labeled "mentally ill" which might result from an involuntary hospitalization, could represent devastating harm.

From an ethical perspective, the decision to involuntarily admit an individual must be justified on the grounds that the overall good of the person is being advanced by the clinician's actions. At the very least, this will require a minimal understanding on the part of the psychiatrist of what it is that the patient believes, values and holds to be his/her best interest, not an easy task considering the time and informational constraints encountered in an emergency room or clinical setting. Nonetheless, in every instance where the possibility of an involuntary hospitalization arises, the psychiatrist needs to honestly evaluate what would best serve the interest of the patient before them, taking into consideration the particular circumstances of the clinical situation, the treatment objectives of the commitment, and the patient's own understanding of his/her personal good. To do anything less is to engage in clinical decision making which has not adequately engaged a moral point of view.

\section{CONSIDERING THE CLINICIAN'S MOTIVES}

As already noted, a clinical decision to admit a patient against his/her wishes should be based squarely upon a concern for the patient's welfare. As Alan Dyer 
notes, "Taken as a whole, the central tenet of the Hippocratic Oath and tradition is the benefit of the patient. The physician must subsume self-interest to what is good for the patient" (6). Unfortunately, in many emergency situations where disposition decisions frequently are made quickly, with incomplete knowledge and information about the patient, it cannot be assumed that involuntary hospitalization decisions are always intended to benefit only the patient.

As noted by one clinician addressing the topic of risk management, promoting . the patient's welfare is usually only part of the clinical picture. The author writes, “... Practicing medicine in modern day America requires familiarity with the scope of legal responsibilities imposed upon the physician as well as having the resources to develop tools to minimize and avoid legal liability. Caring for patients is only part of the business that medicine, for better or worse, has become" (7).

During an era where physicians go to great lengths to limit personal liability and ensure self-protection from lawsuits, psychiatrists will not infrequently err on the safe side because of the belief that there is not enough time, information or capability to consider alternatives consensually with the patient (8). Paul Appelbaum has referred to the practice of involuntary psychiatric hospitalization based on selfprotecting motives as "preventive detention," and describes it as "ways in which clinicians feel compelled by the threat of liability to detain persons who would not otherwise be considered appropriate subjects for psychiatric hospitalizations" (9).

The obvious ethical concern here is a clinician's proclivity to sacrifice what may be in the patient's best interests for reasons which are primarily self-serving and self-protective in nature. Although this is clearly unacceptable from a moral standpoint, I have listened on more than one occasion during post-call conferences as clinicians justify their involuntary admission decisions based on concerns of legal risks alone. This is not to say that liability considerations are of no importance because, unquestionably, they are. However, they need to be viewed as just one component of the clinical decision and should not be allowed to overshadow, and certainly not replace, the pressing moral concerns which are at stake whenever psychiatrists make treatment choices which impact so profoundly upon the lives of others. As a consequence, if we are to honestly assess the moral nature of involuntary hospitalization decisions, greater attention needs to be focused upon identifying the motives which impel our treatment choices.

The following case example illustrates the prominent ethical concerns which ought to be addressed whenever a clinician is faced with the possibility of involuntarily hospitalizing a patient.

\section{CASE STUDY}

D.W. was a 34 year-old, single female with no previous psychiatric history, who was sent to the emergency room of a large teaching hospital under an involuntary detention act initiated by the patient's psychologist. According to the details included in the accompanying paperwork, the patient had reported a depressed mood for the past several weeks and, on that particular morning, had experienced thoughts of killing herself. She denied having a plan but, upon questioning, admitted that she had a gun in her home. When contacted by telephone, the 
outside psychologist stated she initiated the involuntary detention (which authorizes the hospitalization of a person for three days, but which can be rescinded prior to that time by a treating psychiatrist) because she did not know the patient well. She stated she was unsure the patient would present to the emergency room on her own volition. The patient was, therefore, transported to the emergency room by the local police for further evaluation of suicidality.

When the consulting psychiatrist arrived in the emergency room, he found the completed involuntary commitment forms attached to the patient's chart. The emergency room triage physician had written on the chart's facesheet that the patient was suicidal and ordered a psychiatry consult.

On subsequent examination by the psychiatrist, the patient related a history of worsening depression with mild sleep and appetite disturbances over the course of the past several weeks. She identified numerous stressors, most related to her new small business and her unfamiliar role as a manager of other employees. Although she admitted to having fleeting suicidal ideations during this time period, she stated, "I never seriously considered it," and denied the formulation of a plan. Concerns about her depressed mood, as well as the emergence of transient self-destructive thoughts, had impelled her to see a psychologist. On this particular day, she arrived at her psychologist's office at an unscheduled time and requested an appointment because, "I was having thoughts of hurting myself on and off this morning." She added, "I think she (the psychologist) just freaked out when I told her what I had been thinking about, even though I made it clear that I had no intention of hurting myself. Now I'm in this horrible mess."

The psychiatrist discussed with the patient the option of a voluntary admission, but the patient stated she could not afford to be absent from work since her business depended upon her direct involvement. Moreover, she believed her depression would best be treated on an outpatient basis with the option of a voluntary admission at a later date if symptoms did not improve. She was willing to follow-up with her current psychologist the next day.

When asked if she felt "safe" returning home, the patient responded, "Yeah, I think so." When pressed further, she stated, "Well, none of us ever know how we're going to be in a day or two, but I don't think I would ever hurt myself." On further questioning, it was learned that the patient lived by herself. She felt she could not ask a friend to spend the night "and watch over me" because she believed it was unnecessary and too embarrassing to tell others about the recent events leading to her current situation.

The psychiatrist decided not to rescind the involuntary hold and transferred the patient to the local crisis stabilization unit, mindful of the fact that she was unlikely to receive treatment for her depression in that facility. He acknowledged her low suicide risk, but he felt the potential for personal liability was quite high in light of the documented circumstances surrounding the patient's presentation in the emergency room. The patient was transported to the crisis unit and the involuntary hospitalization act was rescinded the following day by that facility's psychiatrist.

\section{DISCUSSION}

Although there is some degree of uncertainty associated with both the clinical and practical issues raised by the case study presented in this paper, it clearly represents an instance in which the practice of defensive psychiatry contributed to the involuntary admission decision. The decision to involuntarily hospitalize this patient was primarily based upon the clinician's self-interest in avoiding possible 
litigation in the event of a suicide, rather than being grounded in a thoughtful assessment of the patient's best interest.

Concerns derived from the principles of beneficence (e.g., harms accrued from the loss of work, the stigma of being labeled mentally ill in a person with no previous psychiatric history, possible rupture of a therapist-patient relationship, and, perhaps most importantly, the low therapeutic potential of an involuntary hospitalization), as well as autonomy (e.g., detaining a person against her wishes, overriding a person's preferences regarding both the timing and the type of further treatment, etc.), should have served as powerful ethical checks to a decision making process primarily driven by self-protective motives. Clearly, it is difficult to ethically justify this hospitalization as an act which advanced the patient's overall good.

\section{SUMMARY}

In summary, I have argued that all clinical decision making must be evaluated for its medical appropriateness, legal defensibility and ethical soundness. Nowhere is this more needed than in the emergency room where decisions regarding the involuntary hospitalization of a person are frequently made under the severe limitations of insufficient time and inadequate information. In this brief paper, I have proposed two ethical considerations, the patient's best interests and the clinician's motives, which might serve as starting points for examining the ethical acceptability of involuntary commitment decisions. This habit of assuming the moral point of view in the clinical setting is designed to not only encourage the practice of ethical reflection but, perhaps more important, to foster the ethical practice of involuntary psychiatric hospitalization in an era of prudent medical risk management. Patients, as persons, have a right to expect nothing less.

\section{REFERENCES}

1. Ramsey P: The Patient as Person. New Haven: Yale University Press, 1975.

2. National Institute of Mental Health. Client/Patient Sample Survey of Inpatient, Outpatient, and Partial Care Programs. Unpublished data. Rockville, Md.: the Institute, 1986.

3. Jonsen A, Siegler M, Winslade W: Clinical Ethics. New York: Macmillan Publishing Co., 1986.

4. Levenson J: "Psychiatric Commitment and Involuntary Hospitalization: An Ethical Perspective." Psychiatric Quarterly, 1986; 58(2):106-112.

5. Veatch R: A Theory of Medical Ethics. New York: Basic Books, 1981.

6. Dyer A: Ethics and Psychiatry: Toward Professional Definition. Washington, D.C.: American Psychiatric Association Press, 1988.

7. Harter-Golder B: "Risk Management for Individual Practices." Journal of Florida Medical Association, 1992; 79(2):409-410.

8. Levenson J: op cit; p. 110-111.

9. Appelbaum P: "The New Preventive Detention: Psychiatry's Problematic Responsibility for the Control of Violence." American Journal of Psychiatry, 1988; 145(7):779-785. 